\title{
Characterization and identification of ISSR markers associated with oil content in sea buckthorn berries
}

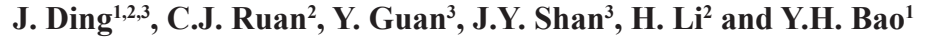 \\ ${ }^{1}$ College of Forestry, Northeast Forestry University, Harbin, \\ Heilongjiang, China \\ ${ }^{2}$ Institute of Plant Resources, Dalian Nationalities University, \\ Dalian, Liaoning, China \\ ${ }^{3}$ Institute of Berries, Heilongjiang Academy of Agricultural Sciences, \\ Suiling, Heilongjiang, China \\ Corresponding authors: C.J. Ruan / Y.H. Bao \\ E-mail: ruan@dlnu.edu.cn
}

Genet. Mol. Res. 15 (3): gmr.15038278

Received December 15, 2015

Accepted January 29, 2016

Published August 18, 2016

DOI http://dx.doi.org/10.4238/gmr.15038278

Copyright (C) 2016 The Authors. This is an open-access article distributed under the terms of the Creative Commons Attribution ShareAlike (CC BY-SA) 4.0 License.

\begin{abstract}
Bioactive oils extracted from sea buckthorn (Hippophae rhamnoides) berries contain highly nutritional and medicinal compounds; however, the oil contents of sea buckthorn berries are very low. Thirteen inter-simple sequence repeat (ISSR) primers were used to identify markers associated with oil content of dry pulp in 51 cultivars and lines, which clustered into three major groups based on 137 polymorphic markers. Dry pulp oil contents in 45 cultivars and lines in Group I ranged from 6.6 to $33.1 \%$; these accessions belonged to $H$. rhamnoides ssp mongolica and its hybrids with $H$. rhamnoides ssp sinensis. Three lines (H. rhamnoides ssp mongolica) in Group II had high dry pulp oil contents (33.7 to $37.5 \%$ ), whereas three lines of
\end{abstract}


hybrids in Group III had low dry pulp oil contents (10.9 to 17.5\%). The dry pulp oil content of $H$. rhamnoides ssp mongolica $(27.2 \pm 0.9 \%)$ was higher than that of hybrids $(12.0 \pm 1.2 \%)(\mathrm{P}<0.01)$. Four ISSR markers $\left(881_{340}, 825_{1000}, 817_{380}\right.$, and $\left.807_{1100}\right)$ had positive association with high dry pulp oil content $(\mathrm{P}<0.01)$ using stepwise multiple regression analysis. The use of these ISSR markers is a potential strategy to select genotypes with high dry pulp oil content and suitable parental combinations for improvement of sea buckthorn berries.

Key words: Hippophae rhamnoides; Oil content; ISSR marker; Association; Stepwise multiple regression analysis

\section{INTRODUCTION}

Sea buckthorn (Hippophae rhamnoides) is deciduous perennial shrub or small tree belonging to the Elaeagnaceae family. This species adapts very well to harsh environments, including conditions of drought, salinity and temperatures ranging from $-40^{\circ}$ to $40^{\circ} \mathrm{C}$ (Ruan et al., 2013). Bioactive oils extracted from sea buckthorn berries contain polyunsaturated fatty acids, vitamins, carotenoids and flavonol glycosides (Ranjith et al., 2006; Lehtonen et al., 2010; Li et al., 2013), although oil contents are only 6 to $12 \%$ in seeds and 1 to $6 \%$ in fresh pulp (Yang and Kallio, 2001; Ruan et al., 2007; Dulf, 2012).

Sea buckthorn is heterozygous and dioecious. All species are diploid $(2 \mathrm{n}=24)$ and wind pollinated. The genus Hippophae contains six species and 12 subspecies, all of which are naturally distributed in Asia and Europe (Ruan et al., 2013). Of these, the two subspecies $H$. rhamnoides ssp sinensis and ssp mongolica are distributed mainly in northern China, Russia, and Mongolia, and have substantial differences in morphological and physiological traits. Many cultivars of $H$. rhamnoides ssp sinensis are fast-growing and highly adaptable to harsh environments, although many have small fruit, many thorns and low oil contents, whereas many cultivars of H. rhamnoides ssp mongolica show promising agronomic and commercial traits including large fruit, fewer thorns and high oil contents (Ruan et al., 2007). For example, oil contents in seeds (12\%) and fresh pulp (6\%) of H. rhamnoides ssp mongolica from Russia were significantly higher than those in seeds $(7.3 \%)$ and fresh pulp $(2.0 \%)$ of $H$. rhamnoides ssp sinensis from China (Yang and Kallio, 2001, 2005). Many superior lines with no or fewer thorns, large fruit and high yield have been selected from hybrids between $H$. rhamnoides ssp mongolica and ssp sinensis, including 'Mengzeza14', 'Ezhongza4' and 'Zaciyou' (Ruan et al., 2013; Yang et al., 2015). However, there have been no reports concerning differences in pulp oil contents between $H$. rhamnoides ssp mongolica and its hybrids with H. rhamnoides ssp sinensis.

DNA markers linked to quantitative trait loci (QTL) can play a vital role in selective breeding programs and help to produce improved varieties (Chhotaray et al., 2015). However, sea buckthorn has a 3-5-year juvenile period during which fruits are not produced, and breeding techniques using marker-assisted selection (MAS) based on a QTL linkage map is time-consuming and labor-intensive (Ruan et al., 2013). As such, it is necessary to first use molecular tools to identify and classify genotypes with increased content of the functional edible oils with nutritional and health benefits.

Several types of molecular markers are available for use in the identification of sea buckthorn genetic relationships including random amplified polymorphic DNA, inter-

Genetics and Molecular Research 15 (3): gmr.15038278 
simple sequence repeats (ISSR), amplified fragment length polymorphism, sequence-related amplified polymorphism, and simple sequence repeat. ISSR markers have been used widely in diverse species (Ruan et al., 2004, Ruan and Li, 2005; Ruan, 2006; Li et al., 2010; Zhao et al., 2014; Bentley, et al., 2015) due to an ability to identify high levels of polymorphism, to reliably differentiate between genotypes (Gramaje et al., 2014) and identify markers associated with desirable traits (Ruan et al., 2009). Using ISSR markers, Tian et al. (2004) found that total molecular variance of $11 \mathrm{H}$. rhamnoides populations mainly existed within populations. ISSR markers were also used to differentiate between different cultivars that were labeled identically and identical cultivars with different names, and to determine the genetic relationship of cultivars with unknown parentage to those with known parentage (Li et al., 2009). Similarly, four ISSR markers associating with resistance to dried-shrink disease of sea buckthorn were identified using stepwise multiple regression analysis (MRA) of resistance indices of 52 sea buckthorn accessions (Ruan et al., 2009). Association of ISSR markers with desirable nutritional and agronomic traits such as $\rho$-cymene, $\gamma$-terpinene, thymol, carvacrol, and borneol contents in forest savory (Khadivi-Khub et al., 2014); sugar and protein contents in mulberry (Kar et al., 2008); antioxidant activity and valerenic acid content in Valeriana jatamansi Jones (Jugran et al., 2013, 2015); and fruit skin color, harvest time and soluble solids in sweet cherry (Ganopoulos et al., 2011) have been detected using MRA methods.

In this study, we first analyzed the genetic relationships of 51 cultivars and lines of $H$. rhamnoides ssp mongolica and its hybrids with $H$. rhamnoides ssp sinensis using 13 ISSR primers. We then tested differences in oil contents of sea buckthorn berry dry pulp between $H$. rhamnoides ssp mongolica and its hybrids. Finally, we detected associations of ISSR markers with dry pulp oil contents using MRA methods. In addition, we discuss potential strategies for selecting genotypes with high dry pulp oil contents and parental combinations that may be ideal for improvement of sea buckthorn berries.

\section{MATERIAL AND METHODS}

\section{Plant materials}

Fifty-one cultivars and lines of sea buckthorn from China and other countries were selected for use in this study (Table 1). All accessions were grown in an orchard at the Institute

Table 1. Name, origin, sub-species, and pedigree of 51 Hippophae rhamnoides cultivars and lines.

\begin{tabular}{|c|c|c|c|}
\hline Name (Abbreviation) & Origin & Sub-species & Pedigree or background \\
\hline $\begin{array}{l}\text { Juren (JR), Jinse (JS), Aertaixinwen (AET), Chuyi (CY), Chengse } \\
\text { (CS), Xiangyang (XY), Hunjin (HJ), Xiaolajiao (XLJ) }\end{array}$ & Russia & $\mathrm{ssp}$ mongolica & Plants introduced from Russia and developed in China \\
\hline Yousheng (YS) & Russia & ssp mongolica & Hybrid of 'Xieerbingkayihao' $\mathrm{x}$ wild 'Katong' in Russia and developed in China \\
\hline Shoudu (SD) & Russia & ssp mongolica & Hybrid of 'Lieninggele' $x$ 'Kashiajiaka' in Russia and developed in China \\
\hline Fenlan (FL) & Finland & ssp mongolica & Selected from seedlings of mixed seeds collected from Finland and developed in China \\
\hline $\begin{array}{l}\text { TF2-13 (TF2-13), TF2-23 (TF2-23), TF2-24 (TF2-24), TF2-25 } \\
\text { (TF2-25), TF2-36 (TF2-36), TF2-ZF (ZF) }\end{array}$ & China & ssp mongolica & Selected female plants from mixed seedlings of ‘Tefengerhao’ from Russia \\
\hline $\begin{array}{l}10-06 \text { (06), 10-47 (47), 10-42 (42), 13-00 (13-00), 13-10 (13-10), 13- } \\
11 \text { (13-11), } 13-14 \text { (13-14), 10-33 (33), 10-34 (34), HD-3 (HD3), } \\
\text { Suiji-1 (SJ1), Suiji-3 (SJ3), Suiji-4 (SJ4), HS-1 (HS1), HS-4 (HS4), } \\
\text { HS-10 (HS10), HS-12 (HS12), HS-14 (HS14), HS-15 (HS15), HS- } \\
18 \text { (HS18), HS-20 (HS20), HS-22 (HS22), Xine-1 (XE1), Xine-2 } \\
\text { (XE2), Xine-3 (XE3) }\end{array}$ & China & ssp mongolica & Selected from seedlings of the mixed seeds of ssp mongolica and developed in China \\
\hline Ezhongza-4 (EZZ4) & China & Hybrid & Selected from hybrids of $H$. rhamnoides $\mathrm{ssp}$ sinensis $\mathrm{x}$ ssp mongolica \\
\hline $\begin{array}{l}\text { Za } 05-21(5-21), \text { Za 1-2 (1-2), Za 05-20 (5-20), Za 05-06 (5-6), Za } \\
13-25(13-25)\end{array}$ & China & Hybrid & Hybrid of 'Yousheng' (H. rhamnoides ssp mongolica) x MK88-01 (H. rhamnoides ssp sinensis) \\
\hline Za 13-19(13-19), Za 13-20(13-20) & China & Hybrid & Hybrid of 'Aertai' (H. rhamnoides ssp mongolica) x HZ-87-12 (H. rhamnoides ssp sinensis) \\
\hline Za 56(56) & China & Hybrid & Hybrid of HS-22 (H. rhamnoides ssp mongolica) x MK88-01 (H. rhamnoides ssp sinensis) \\
\hline
\end{tabular}

All data are from the breeder's register.

Genetics and Molecular Research 15 (3): gmr.15038278 
of Berries, Heilongjiang Academy of Agricultural Sciences, Suiling, China (127 $06^{\prime} \mathrm{E}$, $47^{\circ} 14^{\prime} \mathrm{N}$ ). The orchard has a mean annual rainfall of $551.5 \mathrm{~mm}$ and a mean annual temperature of $1.4^{\circ} \mathrm{C}$, and the local weather conditions are described by the north-temperature continental monsoon climate group (Shan, 2008).

Eleven cultivars of $H$. rhamnoides ssp mongolica were introduced from Russia and Finland, and the remaining 31 lines of $H$. rhamnoides ssp mongolica and nine hybrids between H. rhamnoides ssp mongolica and ssp sinensis were selected and bred in the People's Republic of China. This study focused on testing genetic variation of dry pulp oil contents between $H$. rhamnoides ssp mongolica and its hybrids and identifying the association of ISSR markers with oil contents in dry pulp.

\section{DNA extraction, ISSR amplification, and gel electrophoresis}

Young leaves $(30 \mathrm{~g})$ were collected from one plant of each accession in June 2013. Total genomic DNA (gDNA) was extracted from $0.2 \mathrm{~g}$ fresh leaf tissue following the CTAB-based procedure of Ruan et al. (2004). The quality and concentration of gDNA were evaluated by $1 \%$ $(\mathrm{w} / \mathrm{v})$ agarose gel electrophoresis and measuring the $\mathrm{A}_{260} / \mathrm{A}_{280}$ value (1.8-1.9) using a Nanodrop 2000 spectrophotometer (Thermo Fisher Scientific, Wilmington, DE, USA). PCR ( $20 \mu \mathrm{L})$ was conducted using $2 \mu \mathrm{L} 10 \mathrm{X}$ PCR buffer and final concentrations of $2.5 \mathrm{mM} \mathrm{MgCl}_{2}, 0.2 \mathrm{mM}$ each dNTP, $0.5 \mu \mathrm{M}$ each primer, $30 \mathrm{ng}$ gDNA template, and $2 \mathrm{U}$ Taq DNA polymerase (TaKaRa, Dalian, China). The thermocycler program was set at $90 \mathrm{~s}$ at $94^{\circ} \mathrm{C}$ followed by 45 cycles of $45 \mathrm{~s}$ at $94^{\circ} \mathrm{C}, 45 \mathrm{~s}$ annealing at $53^{\circ}$ to $54^{\circ} \mathrm{C}$ for the different primers (Table 2), and $90 \mathrm{~s}$ extension at $72^{\circ} \mathrm{C}$, followed by a final extension step at $72^{\circ} \mathrm{C}$ for $7 \mathrm{~min}$. Each reaction was stored at $4^{\circ} \mathrm{C}$ until gel analysis. The 13 primers were those reported by Ruan et al. (2009). Samples were amplified in a C1000 Touch ${ }^{\mathrm{TM}}$ Thermal Cycler PCR system (Bio-Rad Laboratories Inc., Foster, CA, USA). The PCR products were separated by electrophoresis on $1.5 \%(\mathrm{w} / \mathrm{v})$ agarose gels and visualized in a GelDoc-It ${ }^{2}$ Imaging System (Ultra-Violet Products Ltd., Upland, CA, USA) after staining with Gold View I (Solarbio Science \& Technology, Beijing, China).

\begin{tabular}{|c|c|c|c|c|c|c|}
\hline Primer & Primer sequence $\left(5^{\prime} \rightarrow 3^{\prime}\right)$ & $\begin{array}{c}\text { Annealing } \\
\text { temperature }\left({ }^{\circ} \mathrm{C}\right)\end{array}$ & $\begin{array}{l}\text { Total number of } \\
\text { ISSR bands }\end{array}$ & $\begin{array}{l}\text { Total polymorphic } \\
\text { number of bands }\end{array}$ & Polymorphism (\%) & PIC \\
\hline UBC807 & AGAGAGAGAGAGAGAGT & 53 & 9 & 9 & 100 & 0.93 \\
\hline UBC 808 & AGAGAGAGAGAGAGAGC & 53 & 12 & 12 & 100 & 0.95 \\
\hline UBC809 & AGAGAGAGAGAGAGAGG & 53 & 10 & 10 & 100 & 0.93 \\
\hline UBC811 & GAGAGAGAGAGAGAGAC & 53 & 10 & 10 & 100 & 0.94 \\
\hline UBC812 & GAGAGAGAGAGAGAGAA & 54 & 10 & 10 & 100 & 0.93 \\
\hline UBC816 & CACACACACACACACAT & 53 & 9 & 8 & 88.9 & 0.93 \\
\hline UBC817 & CACACACACACACACAA & 53 & 10 & 8 & 80 & 0.93 \\
\hline UBC823 & TCTCТСТСТСТСТСТCС & 53 & 10 & 10 & 100 & 0.94 \\
\hline UBC825 & TCTCTCTCTCTCTCTCG & 53 & 13 & 13 & 100 & 0.94 \\
\hline UBC827 & ACACACACACACACACG & 53 & 9 & 8 & 88.9 & 0.92 \\
\hline UBC835 & AGAGAGAGAGAGAGAGYC & 53 & 17 & 17 & 100 & 0.96 \\
\hline UBC881 & GGGTGGGGTGGGGTG & 53 & 14 & 14 & 100 & 0.95 \\
\hline UBC887 & DVDTCTCTCTCTCTCTC & 53 & 9 & 8 & 88.9 & 0.92 \\
\hline Total & & & 142 & 137 & 96.5 & \\
\hline
\end{tabular}

$\mathrm{Y}=(\mathrm{C}, \mathrm{T}) ; \mathrm{D}=(\mathrm{A}, \mathrm{G}, \mathrm{T}) ; \mathrm{V}=(\mathrm{A}, \mathrm{C}, \mathrm{G}) ; \mathrm{PIC}=$ polymorphism information content.

\section{Oil content in dry pulp}

Sea buckthorn leaves and berries were collected from one plant of each accession in

Genetics and Molecular Research 15 (3): gmr.15038278 
June and August 2013, respectively. Fresh fruits were stored at $-46^{\circ} \mathrm{C}$ in sealed plastic bags until analysis. Berries with seeds removed (non-seed tissues) were air dried according to the method of Gutierrez et al. (2008). The oil contents of these tissues (hereafter dry pulp) were measured with a HCY-10 NMR oil content analyzer (Top Instrument CO., LTD, HangZhou, China) according to the protocol of Dong et al. (2011) using three replicates. Dry pulp oil contents of 51 cultivars and lines were grouped into three classes: low $(0.0-21.0 \%)$, moderate $(21.0-32.0 \%)$, and high (>32.0\%). Analysis of variance of oil contents among accessions was performed using the SPSS Statistics 20.0 software (IBM Corp., Armonk, NY, USA).

\section{Data analysis of ISSR markers}

Fragments amplified by each ISSR primer were scored as either " 1 " (present) or " 0 " (absent). Polymorphism information content (PIC) per primer was calculated according the method of Anderson et al. (1993):

$$
1-\sum \mathrm{P}_{\mathrm{ij}}^{2}
$$

where the relative frequency of the $j^{\text {th }}$ band for the $i^{\text {th }}$ primer is summed across all bands for the primer over all cultivars and lines. Genetic similarities between pairs of cultivars and lines were calculated using DICE similarity coefficients based on ISSR matrix data using the software of NTSYSpc version 2.1. Cluster analysis of 51 cultivars and lines was conducted using unweighted pair group analysis (UPGMA) with the SAHN module. A phylogenetic tree was constructed after combining with a graphical heatmap to show dry pulp oil contents using the MeV Software. The goodness-of-fit of the cluster was tested using the MXCOMP (matrix comparison) program, which directly compared the original similarity matrix with the cophenetic value matrix.

Pearson's correlation coefficients were calculated for all ISSR markers and dry pulp oil contents, and were categorized into positive or negative correlation groups. The association of ISSR markers and dry pulp oil contents was estimated by the MRA method using SPSS Statistics 20.0. Oil content was considered a quantitative trait and dependent variable (Virk et al., 1996) whereas the negative and the positive ISSR markers were treated as independent variables. $F$ values with $P$ values between 0.045 and 0.099 were used to include and remove independent variables from the regression equation, respectively (Kar et al., 2008; Ruan et al., 2009). $R^{2}$ denotes the square of $r$, the correlation coefficient.

\section{RESULTS}

\section{Oil contents in dry pulp of sea buckthorn berries}

Among the 51 cultivars and lines, the highest dry pulp oil content $(38.6 \pm 0.1 \%)$ was measured in line TF2-36 (H. rhamnoides ssp mongolica) whereas the lowest $(6.6 \pm 0.1 \%)$ was measured in line 56 (hybrids between H. rhamnoides ssp mongolica and ssp sinensis) (Figure 1). The dry pulp oil contents of 42 cultivars and lines of $H$. rhamnoides $\mathrm{ssp}$ mongolica ranged from 12.3 to $38.6 \%$, and that in nine lines of hybrids was 6.6 to $17.5 \%$. The average oil content of $H$. rhamnoides ssp mongolica $(27.2 \pm 0.9 \%)$ was significantly higher than that in the hybrids $(12.0 \pm 1.2 \%)(P<0.01 ;$ Figure 1$)$.

Genetics and Molecular Research 15 (3): gmr.15038278 


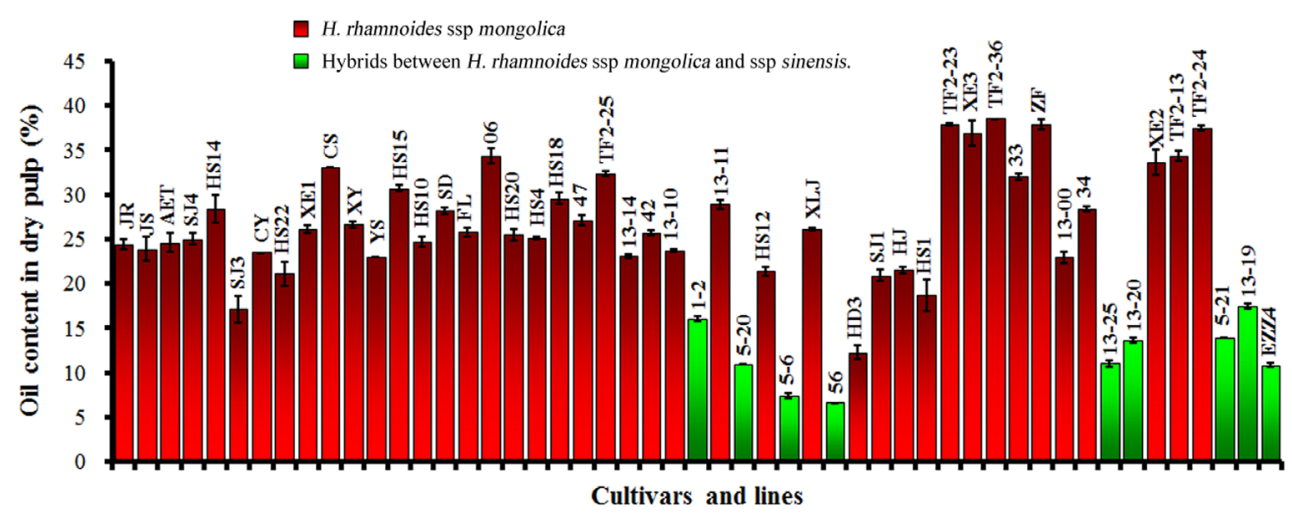

Figure 1. Dry pulp oil contents of 51 sea buckthorn (Hippophae rhamnoides) cultivars and lines. Abbreviations used for the names of cultivars and lines are: JR = Juren; JS = Jinse; AET = Aertaixinwen; CY = Chuyi; CS = Chengse; XY = Xiangyang; HJ = Hunjin; XLJ = Xiaolajiao; YS = Yousheng; SD = Shoudu; FL = Fenlan; TF2-13 (TF2-13); TF2-23 (TF2-23); TF2-24 (TF2-24); TF2-25 (TF2-25); TF2-36 (TF2-36); TF2-ZF (ZF); $10-06$ (06); 10-47 (47); 10-42 (42); 13-00 (13-00); 13-10 (13-10); 13-11 (13-11); 13-14 (13-14); 10-33 (33); 10-34 (34); HD-3 (HD3); Suiji-1 (SJ1); Suiji-3 (SJ3); Suiji-4 (SJ4); HS-1 (HS1); HS-4 (HS4); HS-10 (HS10); HS-12 (HS12); HS14 (HS14); HS-15 (HS15); HS-18 (HS18); HS-20 (HS20); HS-22 (HS22); Xine-1 (XE1); Xine-2 (XE2); Xine-3 (XE3); Ezhongza-4 (EZZ4); Za 05-21 (5-21); Za 1-2 (1-2); Za 05-20 (5-20); Za 05-06 (5-6); Za 13-25 (13-25); Za 13-19 (13-19); Za 13-20 (13-20); Za 56 (56).

\section{ISSR analysis}

Thirteen ISSR primers generated 142 bands among the 51 cultivars and lines, 137 of which $(96.5 \%)$ were polymorphic (Table 2$)$. The total number of bands generated by each primer ranged from 9 (UBC807, UBC816, UBC827, and UBC887) to 17 (UBC835), with a mean of 10.9 bands per primer. Nine primers (those not including primers UBC816, UBC817, UBC827, and UBC887) generated $100 \%$ polymorphism. The PIC per primer ranged from 0.92 to 0.96 with a mean of 0.94 .

\section{Cluster analysis}

DICE coefficients between pairs of the 51 cultivars and lines ranged from 0.302 to 0.935 with a mean value of $0.636 \pm 0.094$. The highest DICE coefficient found (0.935) was between Russian cultivar CY (H. rhamnoides ssp mongolica) and line HS22 (H. rhamnoides ssp mongolica generated from progeny of Russian seeds) (Table 1). The minimum DICE coefficient found (0.302) was between line TF2-24 (selected from mixed female seedlings of $H$. rhamnoides ssp mongolica 'Tefengerhao' from Russia) and line 13-19 (selected from seedlings of H. rhamnoides ssp mongolica 'AET' and H. rhamnoides ssp sinensis line HZ-8712 from China) (Table 1).

At the 0.59 DICE coefficient levels, 51 cultivars and lines were clustered into three groups (Figure 2). The cophenetic correlation ( $r$ ) was 0.858 using the MXCOMP program, thus indicating a good fit between the dendrogram and the original similarity matrix. At the 0.63 DICE coefficient level, Group I was sub-divided into three sub-groups (Ia, Ib, and Ic) (Figure 2). Nine cultivars and 17 lines of H. rhamnoides ssp mongolica and one hybrid were 
clustered into Group Ia; their dry pulp oil contents ranged from 16.1 to $34.4 \%$. In this subgroup, 23 of 27 cultivars and lines had moderate oil contents, three had high oil contents, and one had low oil content. Thirteen cultivars and lines of $H$. rhamnoides ssp mongolica and three lines of hybrids were clustered into Group Ib. Dry pulp oil contents of hybrid lines 5-20, 5-6, and 56 were low, where $H$. rhamnoides ssp mongolica lines TF2-23, XE3, TF2-36, 33, and ZF had high oil contents. In Group Ic, the dry pulp oil contents of hybrid lines 13-25 and 1320 were 11.0 and $13.7 \%$, respectively. In Group II, H. rhamnoides ssp mongolica lines XE2, TF2-13, and TF2-24 had high oil contents (33.7, 34.3, and 37.5\%, respectively). In Group III, hybrid lines 5-21, 13-19, and EZZ4 had low oil contents (14.0, 17.5, and 10.9\%, respectively).

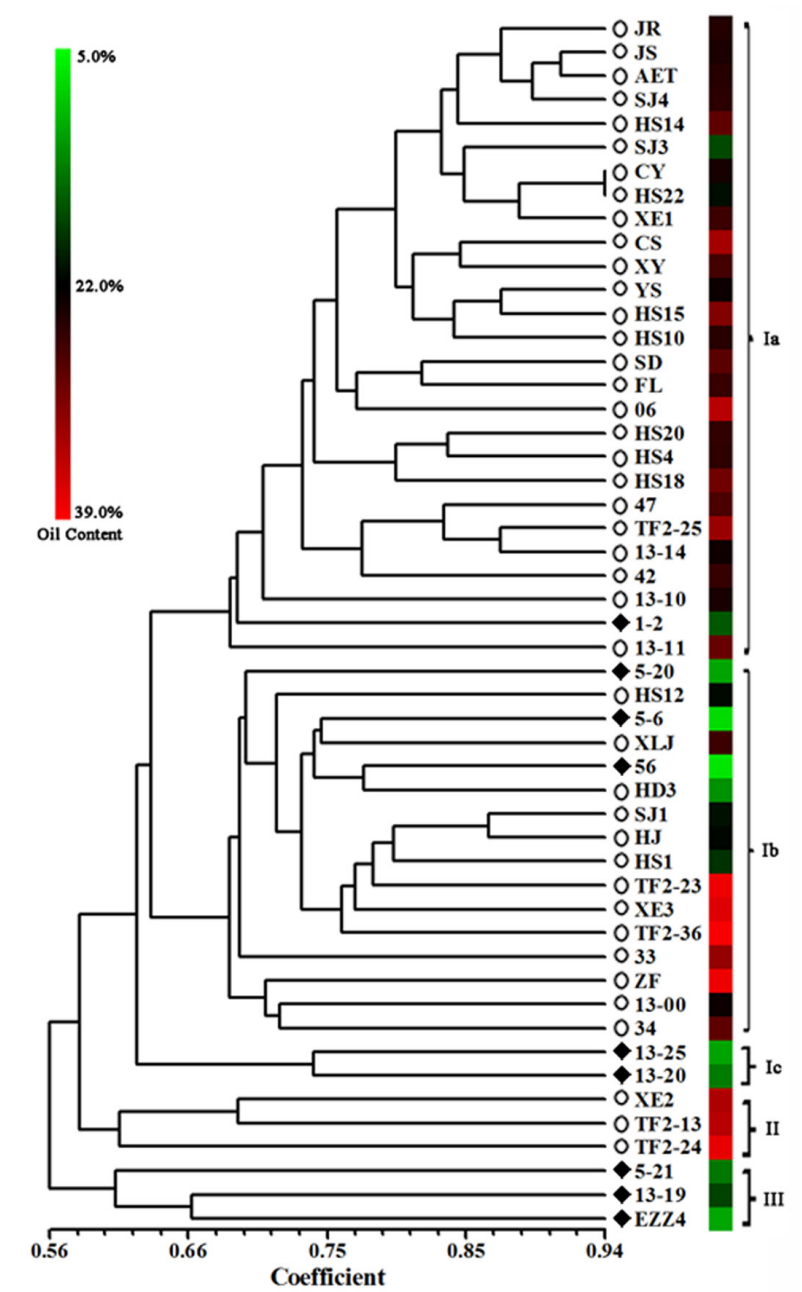

Figure 2. Dendrogram and dry pulp oil contents of 51 sea buckthorn cultivars and lines revealed by cluster analysis of genetic similarity estimates generated by DICE coefficient based on 137 polymorphic ISSR markers. Ia, Ib, Ic, II, and III are the number of groups. Open circles indicate H. rhamnoides ssp mongolica cultivars or lines. Filled diamonds indicate hybrids between $H$. rhamnoides ssp mongolica and ssp sinensis. Abbreviations are the same as in Figure 1.

Genetics and Molecular Research 15 (3): gmr.15038278 


\section{Association of ISSR markers with oil contents in dry pulp}

The MRA results indicated that there was a significant correlation between four ISSR markers and dry pulp oil content (Table 3$)$. Specifically, four markers $\left(881_{340}, 825_{1000}, 817_{380}\right.$, and $807_{1100}$ ) (Table 4) showed positive correlation with high dry pulp oil content. Of these, marker $881_{340}$ had substantial positive correlation $(r=0.489, \mathrm{P}=0.000, t=3.929)$ with high oil content in dry pulp. Conversely, four markers $808_{1050}, 807_{380}, 827_{370}$, and $809_{300}$ (Table 4) showed negative correlation with dry pulp oil content. Of these, marker $808_{1050}$ had a substantial negative correlation $(r=-0.707, \mathrm{P}=0.000, t=-7.000)$ with high oil content in dry pulp.

\begin{tabular}{|c|c|c|c|c|c|c|c|c|}
\hline Correlation & Dimensions $^{\dagger}$ & Markers & Un-standardized coefficient beta & SE & Standardized coefficient beta & $t$ value & $P$ value & $r$ \\
\hline \multirow[t]{10}{*}{ Positive } & I & $881_{340}$ & 14.645 & 3.727 & 0.489 & 3.929 & 0.000 & 0.489 \\
\hline & \multirow[t]{2}{*}{ II } & $881_{340}$ & 13.794 & 3.380 & 0.461 & 4.081 & 0.000 & 0.460 \\
\hline & & 8251000 & 13.327 & 3.862 & 0.390 & 3.451 & 0.001 & 0.389 \\
\hline & \multirow[t]{3}{*}{ III } & $881_{340}$ & 12.990 & 3.054 & 0.434 & 4.254 & 0.000 & 0.432 \\
\hline & & 8251000 & 13.640 & 3.480 & 0.399 & 3.919 & 0.000 & 0.398 \\
\hline & & $817_{380}$ & 5.901 & 1.694 & 0.355 & 3.483 & 0.001 & 0.354 \\
\hline & \multirow[t]{4}{*}{ IV } & $881_{340}$ & 13.669 & 2.801 & 0.457 & 4.881 & 0.000 & 0.453 \\
\hline & & 8251000 & 13.029 & 3.188 & 0.381 & 4.086 & 0.000 & 0.379 \\
\hline & & 817380 & 5.086 & 1.570 & 0.306 & 3.240 & 0.002 & 0.301 \\
\hline & & $807_{1100}$ & 12.495 & 3.911 & 0.302 & 3.195 & 0.003 & 0.297 \\
\hline \multirow[t]{10}{*}{ Negative } & I & $808_{1050}$ & -15.640 & 2.234 & -0.707 & -7.000 & 0.000 & -0.707 \\
\hline & \multirow[t]{2}{*}{ II } & $808_{1050}$ & -14.421 & 2.051 & -0.652 & -7.032 & 0.000 & -0.642 \\
\hline & & 807380 & -7.489 & 2.167 & -0.320 & -3.456 & 0.001 & -0.316 \\
\hline & \multirow[t]{3}{*}{ III } & $808_{1050}$ & -12.046 & 2.168 & -0.545 & -5.556 & 0.000 & -0.482 \\
\hline & & $807_{380}$ & -7.014 & 2.067 & -0.300 & -3.393 & 0.001 & -0.294 \\
\hline & & 827370 & -5.700 & 2.286 & -0.244 & -2.493 & 0.016 & -0.216 \\
\hline & \multirow[t]{4}{*}{ IV } & $808_{1050}$ & -11.384 & 2.093 & -0.515 & -5.439 & 0.000 & -0.451 \\
\hline & & $807_{380}$ & -5.511 & 2.080 & -0.236 & -2.649 & 0.011 & -0.220 \\
\hline & & 827370 & -6.601 & 2.221 & -0.282 & -2.973 & 0.005 & -0.247 \\
\hline & & $809_{300}$ & -3.427 & 1.476 & -0.206 & -2.321 & 0.025 & -0.193 \\
\hline
\end{tabular}

†Denotes the dimensions for different steps under stepwise MRA, where the marker(s) of previous step(s) are included in the succeeding step.

\begin{tabular}{|c|c|c|c|c|c|}
\hline Correlation & Markers $^{\dagger}$ & $R^{2}$ & $R^{2}$ change & F change & $P$ value of $F$ change \\
\hline \multirow[t]{4}{*}{ Positive } & $881_{340}$ & 0.240 & 0.240 & 15.439 & 0.000 \\
\hline & +8251000 & 0.391 & 0.151 & 11.910 & 0.001 \\
\hline & $+817_{380}$ & 0.516 & 0.125 & 12.134 & 0.001 \\
\hline & $+807_{1100}$ & 0.604 & 0.088 & 10.208 & 0.003 \\
\hline \multirow[t]{4}{*}{ Negative } & $808_{1050}$ & 0.500 & 0.500 & 48.994 & 0.000 \\
\hline & +807380 & 0.600 & 0.100 & 11.941 & 0.001 \\
\hline & +827370 & 0.646 & 0.047 & 6.214 & 0.016 \\
\hline & $+809_{300}$ & 0.683 & 0.037 & 5.389 & 0.025 \\
\hline
\end{tabular}

†"+" denotes the inclusion of marker(s) in the preceding step(s) in the stepwise MRA.

\section{DISCUSSION}

According to ISSR marker analysis, 51 cultivars and lines of $H$. rhamnoides ssp mongolica and its hybrids with $H$. rhamnoides ssp sinensis were clustered into three major groups that were in good agreement with taxonomic classifications and available pedigree and genetic background information. The coefficient of gene differentiation between $H$. rhamnoides ssp mongolica and its hybrids was 0.059 , which indicated that $5.9 \%$ of total 
genetic difference occurred between one subspecies and its hybrids with another subspecies, whereas $94.1 \%$ existed within subspecies (Ding et al., 2015).

According to the cluster analysis (Figure 2) and oil contents of 51 cultivars and lines (Figure 1), accessions that clustered into the same sub-groups had similar dry pulp oil contents, and that the oil content of $H$. rhamnoides ssp mongolica was significantly higher than that of the hybrids. Lines 13-25 and 13-20 in Group Ic and lines 5-21, 13-19, and EZZ4 in Group III had low oil contents $(11.1,13.7,14.0,17.5$, and 10.9\%, respectively). These lines were selected from hybrids between $H$. rhamnoides ssp mongolica and ssp sinensis. In contrast, lines XE2, TF2-13, and TF2-24 in Group II had high oil contents (33.7, 34.3, and 37.5\%, respectively) and all belonged to $H$. rhamnoides ssp mongolica. These results indicated that the cluster analyses based on ISSR markers could provide useful taxonomic information regarding pre-selection of cultivars and lines with high dry pulp oil contents.

The four ISSR markers associated with high oil content in dry pulp, which were first identified in this study, could also be used to identify sea buckthorn germplasm with high oil contents before maturity, and the four markers associated with low oil content in dry pulp could be used to eliminate germplasm with low oil content before entering the maturity. Although most ISSR markers are dominant markers and not appropriate for analysis of heterozygosity (Bentley et al., 2015), the most important application of this study was that the four ISSR markers could not only provide potential strategies for selecting genotypes with high oil contents and parental combinations for improving desirable agronomic traits in a sea buckthorn breeding program, but could also provide the foundation for the conversion of specific ISSR fragments into sequence-characterized amplified region (SCAR) markers, which could be directly used in early molecular diagnosis of oil content in sea buckthorn germplasm. For example, three reliable SCAR markers that were derived from six species-specific ISSR fragments were subsequently used to identify five necrophagous fly species (He et al., 2007).

Fresh and dry pulp oil contents of $H$. rhamnoides ssp mongolica were previously shown to be higher than those of $H$. rhamnoides ssp sinensis (Ruan and Li, 2001; Yang and Kallio, 2002, 2005). In this study, our results first indicated that the dry pulp oil content of H. rhamnoides ssp mongolica was significantly higher than those of hybrids (27.2 vs 12.0\%). Whereas pulp traits of sea buckthorn berries have genetic characteristics of the female parent genotype (Oomah, 2005), oil contents may also be affected by the male parent genotype due to pollen xenia. For example, 'Yousheng' (H. rhamnoides ssp mongolica) has high dry pulp oil content $(23.0 \%)$ whereas line MK88-01 (H. rhamnoides ssp sinensis) has low dry pulp oil content (6.0\%) (Ruan and Li, 2001). However, the dry pulp oil contents of lines 5-20 and 5-6, which were hybrids between 'Yousheng' and MK88-01, were only 10.98 and 7.39\%, respectively. Pollen xenia, which is defined as the effect of pollen sources on fruit quality and quantity, has been reported in pistachio (Cran and Iwakiri, 1980), hazelnut (Weingartner et al., 2004) and maize (Fattahi et al., 2014). For example, the use of pollen from small-seeded pistachio cultivars was shown to generate small seeds in cultivars that typically produce large seeds (Cran and Iwakiri, 1980).

As sea buckthorn is highly heterozygous and has a 3-5-year juvenile period before fruit production, MAS breeding based on a QTL linkage map to select materials with high oil contents in a conventional breeding program is overly time-consuming. As such, the results of clustering analysis and ISSR markers that are associated with high oil contents will play a vital and time-saving role in identifying and classifying genotypes that have high oil contents. The present study also presents the possibility of converting specific ISSR markers into SCAR

Genetics and Molecular Research 15 (3): gmr.15038278 
markers in future marker-assisted breeding programs, to greatly improve oil contents of sea buckthorn.

\section{Conflicts of interest}

The authors declare no conflict of interest.

\section{ACKNOWLDGMENTS}

Research supported by the Natural Science Foundation of China (Project \#31570681 and \#31100489) and a Marie Curie International Incoming Fellowship from the 7th European Community Framework Program (Project \#PIIF-GA-2010-272048 and \#PIIFRGA-2010-910048).

\section{REFERENCES}

Anderson JA, Churchill GA, Autrique JE, Sorrells ME, et al. (1993). Optimizing parental selection for genetic linkage maps. Genome 36: 181-186. http://dx.doi.org/10.1139/g93-024

Bentley L, Barker NP and Dold AP (2015). Genetic diversity of the endangered Faucaria tigrina (Aizoaceae) through ISSR "fingerprinting" using automated fragment detection. Biochem. Syst. Ecol. 58: 156-161. http://dx.doi.org/10.1016/j. bse.2014.11.012

Chhotaray C, Mishra J, Sahoo PK, Das S, et al. (2015). Development of twenty-seven genic SSR markers and screening for their association with resistance to Aeromonas hydrophila infection in rohu (Labeo rohita, Hamilton). Biochem. Syst. Ecol. 58: 85-90. http://dx.doi.org/10.1016/j.bse.2014.11.002

Cran JC and Iwakiri BT (1980). Xenia and metaxenia in pistachio. HortScience 15: 184-185.

Ding J, Ruan CJ, Bao YH, Guan Y, et al. (2015). Analysis of genetic relationships in sea buckthorn (Hippophae rhamnoides) germplasm from China and other countries using ISSR markers. J. Hortic. Sci. Biotechnol. 90: 599606. http://dx.doi.org/10.1080/14620316.2015.11668721

Dong XL, Bai PL, Wang JM and Ruan CJ (2011). Comparative study on determination of seed oil content of energy plants by using NMR and Soxhlet extraction. Renew. Energ. Resour 29: 21-24.

Dulf FV (2012). Fatty acids in berry lipids of six sea buckthorn (Hippophae rhamnoides L., subspecies carpatica) cultivars grown in Romania. Chem. Cent. J. 6: 106. http://dx.doi.org/10.1186/1752-153X-6-106

Fattahi R, Mohammadzedeh M and Khadivi-Khub A (2014). Influence of different pollen sources on nut and kernel characteristics of hazelnut. Sci. Hortic. (Amsterdam) 173: 15-19. http://dx.doi.org/10.1016/j.scienta.2014.04.031

Ganopoulos IV, Kazantzis K, Chatzicharisis I, Karayiannis I, et al. (2011). Genetic diversity, structure and fruit trait associations in Greek sweet cherry cultivars using microsatellite based (SSR/ISSR) and morpho-physiological markers. Euphytica 181: 237-251. http://dx.doi.org/10.1007/s10681-011-0416-Z

Gramaje D, Leon M, Santana M, Crous PW, et al. (2014). Multilocus ISSR markers reveal two major genetic groups in Spanish and South African populations of the grapevine fungal pathogen Cadophora luteo-olivacea. PLoS One 9: e110417. http://dx.doi.org/10.1371/journal.pone.0110417

Gutierrez LF, Ratti C and Belkacemi K (2008). Effects of drying method on the extraction yields and quality of oils from Quebec sea buckthorn (Hippophae rhamnoides L.) seeds and pulp. Food Chem. 106: 896-904. http://dx.doi. org/10.1016/j.foodchem.2007.06.058

He L, Wang SB, Miao XX, Wu H, et al. (2007). Identification of necrophagous fly species using ISSR and SCAR markers. Forensic Sci. Int. 168: 148-153. http://dx.doi.org/10.1016/j.forsciint.2006.07.006

Jugran A, Rawat S, Dauthal P, Mondal S, et al. (2013). Association of ISSR markers with some biochemical traits of Valeriana jatamansi Jones. Ind. Crops Prod. 44: 671-676. http://dx.doi.org/10.1016/j.indcrop.2012.09.004

Jugran AK, Bhatt ID and Rawat RS (2015). Identification of ISSR markers associated with valerenic acid content and antioxidant activity in Valeriana jatamansi Jones in the West Himalaya. Mol. Breed. 35: 73. http://dx.doi. org/10.1007/s11032-015-0241-5

Kar PK, Srivastava PP, Awasthi AK and Urs SR (2008). Genetic variability and association of ISSR markers with some biochemical traits in mulberry (Morus ssp.) genetic resources available in India. Tree Genet. Genomes 4: 75-83.

Genetics and Molecular Research 15 (3): gmr.15038278 
http://dx.doi.org/10.1007/s11295-007-0089-x

Khadivi-Khub A, Karimi E and Hadian J (2014). Population genetic structure and trait associations in forest savory using molecular, morphological and phytochemical markers. Gene 546: 297-308. http://dx.doi.org/10.1016/j. gene.2014.05.062

Lehtonen HM, Lehtinen O, Suomela JP, Viitanen M, et al. (2010). Flavonol glycosides of sea buckthorn (Hippophae rhamnoides ssp. sinensis) and lingonberry (Vacciniumvitis-idaea) are bioavailable in humans and monoglucuronidated for excretion. J. Agric. Food Chem. 58: 620-627. http://dx.doi.org/10.1021/jf9029942

Li H, Ruan CJ and Teixeira da Silva JA (2009). Identification and genetic relationship based on ISSR analysis in a germplasm collection of sea buckthorn (Hippophae L.) from China and other countries. Sci. Hortic. (Amsterdam) 123: 263-271. http://dx.doi.org/10.1016/j.scienta.2009.08.007

Li H, Ruan CJ, Teixeira da Silva JA and Liu BQ (2010). Associations of SRAP markers with dried-shrink disease resistance in a germplasm collection of sea buckthorn (Hippophae L.). Genome 53: 447-457. http://dx.doi.org/10.1139/G10$\underline{020}$

Li W, Ruan CJ, Teixeira da Silva JA, Guo H, et al. (2013). NMR metabolomics of berry quality in sea buckthorn (Hippophae L.). Mol. Breed. 31: 57-67. http://dx.doi.org/10.1007/s11032-012-9768-x

Oomah BD (2005). Sea buckthorn lipid. Global Seabuckthorn Res. Dev. 3: 1-14.

Ranjith A, Kumar KS, Venugopalan VV, Arumughan C, et al. (2006). Fatty acids, tocols, and carotenoids in pulp oil of three sea buckthorn species (Hippophae rhamnoides, H. salicifolia and H. tibetana) grown in the Indian Himalayas. J. Am. Oil Chem. Soc. 83: 359-364. http://dx.doi.org/10.1007/s11746-006-1213-z

Ruan CJ (2006). Genetic relationships among some sea buckthorn cultivars from China, Russia and Mongolia using AFLP markers. J. Hortic. Sci. Biotechnol. 81: 409-414. http://dx.doi.org/10.1080/14620316.2006.11512081

Ruan CJ and Li D (2001). Summarize of study on the oil content of seabuckthorn and influence factors. Xibei Zhiwu Xuebao 21: 207-214.

Ruan CJ and Li D (2005). AFLP fingerprinting analysis of some cultivated varieties of sea buckthorn (Hippophae rhamnoides). J. Genet. 84: 311-315. http://dx.doi.org/10.1007/BF02715802

Ruan CJ, Qin P, Zheng JW and He ZX (2004). Genetic relationships among some cultivars of sea buckthorn from China, Russia and Mongolia based on RAPD analysis. Sci. Hortic. (Amsterdam) 101: 417-426. http://dx.doi.org/10.1016/j. $\underline{\text { scienta.2003.11.013 }}$

Ruan CJ, Teixeira da Silva JA, Jin H, Li H, et al. (2007). Research and biotechnology in sea buckthorn (Hippophae ssp.). Med. Aromat. Plant Sci. Biotechnol. 1: 47-60.

Ruan CJ, Li H and Mopper S (2009). Characterization and identification of ISSR markers associated with resistance to dried-shrink disease in sea buckthorn. Mol. Breed. 24: 255-268. http://dx.doi.org/10.1007/s11032-009-9288-5

Ruan CJ, Rumpunen K and Nybom H (2013). Advances in improvement of quality and resistance in a multipurpose crop: sea buckthorn. Crit. Rev. Biotechnol. 33: 126-144. http://dx.doi.org/10.3109/07388551.2012.676024

Shan JY (2008). Study on main genetic variation characteristics of hybrid offspring of macro-fruit sea buckthorn. Global Sea buckthorn. Res. Dev. 6: 14-17.

Tian CJ, Lei YD, Shi SH, Nan P, et al. (2004). Genetic diversity of sea buckthorn (Hippophae rhamnoides) populations in northeastern and northwestern China as revealed by ISSR markers. New For. 27: 229-237. http://dx.doi.org/10.1023/ B:NEFO.0000022224.59436.7a

Virk PS, Ford-Lloyd BV, Jackson MT, Pooni HS, et al. (1996). Predicting quantitative variation within rice germplasm using molecular markers. Heredity 76: 296-304. http://dx.doi.org/10.1038/hdy.1996.43

Weingartner U, Camp KH and Stamp P (2004). Impact of male sterility and xenia on grain quality traits of maize. Eur. J. Agron. 21: 239-247. http://dx.doi.org/10.1016/j.eja.2003.08.006

Yang BR and Kallio H (2001). Fatty acid composition of lipids in sea buckthorn (Hippophae rhamnoides L.) berries of different origins. J. Agric. Food Chem. 49: 1939-1947. http://dx.doi.org/10.1021/jf001059s

Yang BR and Kallio H (2002). Composition and physiological effects of sea buckthorn (Hippophae) lipids. Trends Food Sci. Technol. 13: 160-167. http://dx.doi.org/10.1016/S0924-2244(02)00136-X

Yang BR and Kallio H (2005). Bioactive components of berries of three subspecies of sea buckthorn. Global Sea Buckthorn Res. Dev. 1: 1-4.

Yang G, Ding J, Wu LR, Duan YD, et al. (2015). A new strategy for complete identification of sea buckthorn cultivars by using random amplified polymorphic DNA markers. Genet. Mol. Res. 14: 1836-1845. http://dx.doi.org/10.4238/2015. March.13.12

Zhao LH, Liu HM, Cai GZ and Xia MZ (2014). Assessment of the genetic diversity and genetic relationships of Lilium in China using ISSR markers. Biochem. Syst. Ecol. 55: 184-189. http://dx.doi.org/10.1016/j.bse.2014.03.024

Genetics and Molecular Research 15 (3): gmr.15038278 